\title{
Editorial
}

\section{Molecular pathology of solid tumours: translating research into clinical practice. Introduction and overview}

Research in pathology has increasingly come to involve molecular techniques, so that these are currently routine in academic histopathology and genetics laboratories. Molecular markers-largely from tumours, but also from the germline-have great potential for diagnosis, for directing treatment, and as indicators of outcome. However, in general, clinical practice has lagged behind research in molecular histopathology. This is in contrast to clinical genetics, in which cloning of disease genes has usually led to the introduction of molecular testing soon afterwards.

The question remains unanswered as to why histopathology departments have been slower to instigate molecular testing; but there are several clues. Is medical science at fault for not providing useful molecular markers? Are there problems bringing together the expertise from National Health Service (NHS) laboratories of molecular genetics, cytogenetics, and histopathology? Is there not only an inevitable lack of funding, but also an absence of sympathy for molecular techniques? Is there a lack of coordination between different groups, and could the Royal College of Pathologists act as a force to drive forward molecular pathology in the NHS?

To examine these questions, and working from the premise that molecular testing of tumours is potentially beneficial, a symposium was held at the Royal College of Pathologists on 24 February last year. Several papers from this symposium are reported in this issue of Molecular Pathology and others will follow in subsequent issues.

The meeting began with lectures on the molecular techniques that could be applied to the analysis of tumours. Rebecca Roylance ${ }^{1}$ spoke on molecular and cytogenetic methods of detecting genetic gains and losses in cancers, including the use of tissue microarrays. Ian Frayling presented an overview of methods for mutation detection, ${ }^{2}$ including a brief reference to the early detection of tumour cells in blood or other samples, such as stool or urine. Massimo Pignatelli showed how techniques such as immunohistochemistry and in situ hybridisation could compliment other molecular techniques. ${ }^{3}$

Nigel Carter spoke on the topical subject of DNA, mRNA, and protein microarray technology. In principle, the first microarrays are available for clinical use in detecting the high level amplification of certain oncogenes; more general use of such "CGH (comparative genomic hybridisaton) chips" (DNA probe and target) for detecting losses and low level gains is awaited. Expression microarrays (cDNA target and probe) are already used routinely in many research laboratories and can provide a molecular profile of a tumour at presentation, after treatment, and at relapse. Other types of microarrays can be used for nucleic acid sequencing or polymorphism typing. Protein expression microarrays promise to provide complementary data to mRNA expression arrays. The unanswered question is whether the number of useful molecular targets in clinical practice will be sufficient to warrant molecular microarray technology, or whether "more tumours fewer target methods" such as tissue microarrays will be more useful. Owing to the rapid evolution of microarray technology, Nigel Carter's presentation is not detailed further in this volume, but readers are referred to recent articles on this subject. ${ }^{4-9}$

After the presentations on molecular methods, speakers gave talks on the theme "What can we do now?". These talks addressed the current state of research into molecular markers of tumour behaviour, with the aim of assessing whether or not molecular pathology could usefully be introduced into clinical practice in the near future. Sunil Lakhani talked about breast cancer, ${ }^{10}$ Richard Houlston discussed colorectal cancer, ${ }^{11}$ Margaret Knowles considered urogenital tumours, ${ }^{12}$ and Simon Herrington lectured on gynaecological malignancies. ${ }^{13}$ Each lecture was notable for the relatively small number of molecular targets that each speaker thought currently to be of potential use for clinical practice, largely owing to the insufficient size and inconsistent results of the research studies. Nevertheless, every speaker was convinced that the future lay in widespread molecular testing (although no-one was prepared to forecast the death of "traditional" histopathology!).

The subject of funding for molecular pathology in the NHS was addressed by Richard Turner, who presented a positive view about how to put a successful case for local funding. ${ }^{14}$ The greater problem of how to obtain stable, national funding remained.

The following talks by Mohammad Ilyas and Ian Tomlinson considered practical issues, such as: which NHS laboratory-histopathology or genetics or some integrated unit - would be best placed to carry out the work; whether work could occur without large capital investment; the current lack of feasibility of undertaking molecular pathology in every district hospital; whether training in pathology should contain some molecular element; and the need for some central body to decide on which molecular tests were cost effective. ${ }^{15}$ It was felt that convincing physicians, surgeons, and purchasers of the usefulness of molecular pathology was the major obstacle to be overcome, and that this depended on excellent scientific evidence. It was suggested that molecular pathology could usefully start by testing colorectal cancers for microsatellite instability and cervical tumours for human papillomavirus types. It was also proposed that a committee of molecular pathology should be set up under the auspices of the Royal College of Pathologists to promote and assess the need for molecular testing of tumours in the NHS.

Lively discussion followed, led by both molecular geneticists and histopathologists, with focus on the practical issues of setting up molecular pathology and the 
justification for starting testing in the near future. It will be interesting to see if and how the Royal College addresses these issues.

\section{TOMLINSON}

Molecular and Population Genetics Laboratory, Imperial Cancer Research Fund, 44 Lincoln's Inn Fields, London WC2A 3PX, UK

1 Roylance RR. Methods of molecular analysis: assessing losses and gains in tumours. F Clin Pathol: Mol Pathol 2001 [In press.]

2 Frayling IM. Molecular methods: mutation detection. 7 Clin Pathol: $M o$ Pathol 2001 [In press.]

Campbell, RJ, Pignatelli M. Molecular histology in the study of solid tumours. f Clin Pathol: Mol Pathol 2001 [In press.]

4 Hacia JG. Resequencing and mutational analysis using oligonucleotide microarrays. Nat Genet 1999;21:42-7.

5 Hacia JG, Fan JB, Ryder O, et al. Determination of ancestral alleles for human single-nucleotide polymorphisms using high-density oligonucleotide arrays. Nat Genet 1999;22:164-7.
6 Hughes TR, Roberts CJ, Dai H, et al. Widespread aneuploidy revealed by DNA microarray expression profiling. Nat Genet 2000;25:333-7.

7 Penn SG, Rank DR, Hanzel DK, et al. Mining the human genome using microarrays of open reading frames. Nat Genet 2000;26:315-18.

8 Pollack JR, Perou CM, Alizadeh AA, et al. Genome-wide analysis of DNA copy-number changes using cDNA microarrays. Nat Genet 1999;23:41-6. 9 Scherf U, Ross DT, Waltham M, et al. A gene expression database for the molecular pharmacology of cancer. Nat Genet 2000;24:236-44.

10 Lakhani S. What we could do now: molecular pathology of breast cancer. $\mathcal{F}$ Clin Pathol: Mol Pathol 2001 [In press.]

11 Houlston RS. What we could do now: molecular pathology of colorectal cancer. F Clin Pathol: Mol Pathol 2001;54:206-14.

12 Knowles MA. What we could do now: molecular pathology of bladder cancer. 7 Clin Pathol: Mol Pathol 2001;54:215-21.

13 Herrington CS. What we could do now: molecular pathology of gynaecological cancer. F Clin Pathol: Mol Pathol 2001;54:222-4.

14 Turner RD. Commissioning laboratory services. 7 Clin Pathol: Mol Pathol 2001;54:225-6.

15 Tomlinson IPM, Ilyas M. Molecular pathology of solid tumours: some practical suggestions for translating research into clinical practice. 7 Clin Pathol: Mol Pathol 2001;54:203-5.

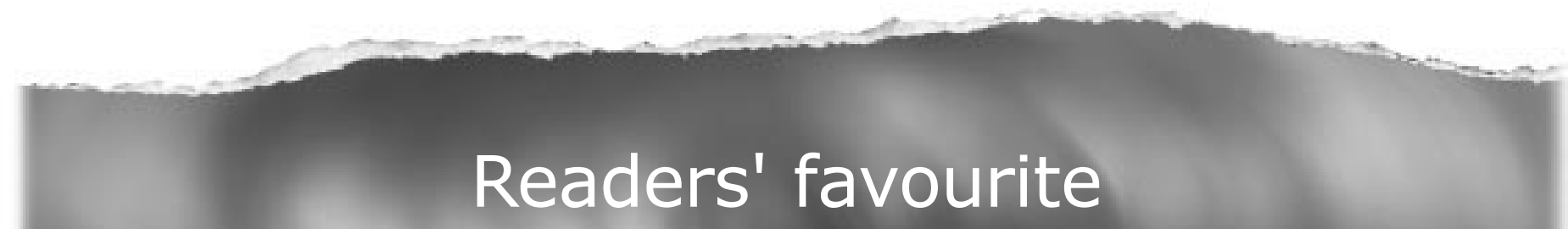

Top 10

Click on the "Top 10" button on the homepage to see which are the best read articles each month

www.jclinpath.com 